\title{
DE LA TEORÍA DE LA REPRESENTACIÓN A UNA DEMOCRACIA REPRESENTATIVA DEBILITADA. INCORPORACIÓN DE LA PERSPECTIVA DE GÉNERO
}

\author{
María Macías Jara \\ mmacias@comillas.edu \\ Universidad Pontificia Comillas - España
}

Recibido: 26-02-2016

Aceptado: 31-05-2016

\section{Resumen}

Las bases consolidadas de la conocida Teoría de la representación siguen cobrando actualidad ante la imposibilidad de articular pactos y consensos desoyendo los intereses y deseos que el cuerpo electoral, pueblo soberano indivisible, manifiesta a través del ejercicio de la democracia representativa. Los diputados y diputadas comulgan libremente con la ideología de partido que escogen, pero cuando el electorado les sitúa como parte integrante de un Parlamento, surge en ellos una responsabilidad que no parecen entender en los tiempos actuales y que tiene que ver con la condición de representantes de un pueblo soberano, en el que aún permanece excluida la mitad de la Humanidad y de la Nación soberana, de modo que la categorización bien sea de sujetos, bien de ideologías en el parlamento no tiene cabida ni ha de impedir la gobernanza de un Estado social y democrático de Derecho al que se encuentran vinculados.

Palabras Clave: Democracia, representación política, soberanía popular, igualdad de género.

\begin{abstract}
The consolidated bases of the well-known Theory of the representation became topical before the inability to articulate agreements and consensuses ignoring the interests and desires that the voting population, indivisible sovereign people, expresses across the exercise of the representative democracy. The congressmen and comgresswomen agree freely with the ideology of the party they choose, but when the electorate places them as an integral part of a Parliament, a responsibility that the current representatives do not seem to understand arises, and it is connected with the condition of representatives of a sovereign people, in which half of the Humanity and of the sovereign Nation is put aside, so that the categorization of subjects or ideologies has no place in the Parliament nor has to prevent the governance of a social and democratic State of Law to which they are linked.
\end{abstract}

Keywords: Democracy, political representation, popular sovereignty, equality of gender. 


\section{Introduction}

En el presente estudio, se ha tratado de realizar un recorrido por la clásica Teoría de la representación a fin de poner de manifiesto cómo esa construcción encierra premisas que aún quedan por consolidar en la actualidad porque la imposibilidad de los políticos actuales de tomar decisiones y de buscar pactos o consensos, esto es, en definitiva, de hacer política, supone la falta de comprensión por los mismos de las premisas básicas de la conocida Teoría de la representación política.

Ante esta incapacidad de comprender las funciones de un gobierno representativo, se pretende con estas reflexiones, en primer lugar, retomar las bases de la representación para evidenciar que en la clase política actual se están olvidando los pilares fundamentales que son útiles para la democracia representativa. En segundo lugar, poner de relieve, que, sin embargo, se están agudizando, precisamente, los posibles defectos o vicios del sistema representativo, de modo que los ideales quedan abandonados y los logros parecen convertirse en deficiencias de la Teoría de la representación tal y como se fraguó.

Tras realizar estas reflexiones, se alude a la idea de soberanía con el fin de resaltar que la clase política se olvida a menudo de que el pueblo es el soberano. En este sentido, igual que se olvida de que la soberanía reside en el pueblo, se olvida de que ese pueblo se encuentra conformado por hombres y mujeres, con lo que los representantes desoyen en este plano lo que les vincula al Estado, esto es; la idea de soberanía, ante la ineficacia para el diálogo político para el que pueblo les ha situado en el cargo representativo y la idea de democracia, una que necesariamente ha de ser paritaria para que lo sea.

Es en este plano que se realiza una importante conexión desde una perspectiva de género sobre quién es el titular de tal soberanía, partiendo de la incompletud de una democracia que no incluyó ni aún incluye al género femenino como base contractual de un posible nuevo pacto social que apueste por el diálogo e interactúe desde la base inclusiva de toda la ciudadanía. No obstante, en esta ocasión, no se ha optado por elaborar un estudio centrado exclusivamente en la igualdad de género ${ }^{1}$, sino en realizar una reflexión acerca del estado de la Teoría de la representación incorporando las posibles afectaciones o implicaciones que esta democracia debilitada vuelca sobre la representación femenina y la igualdad efectiva de género.

\footnotetext{
${ }^{1}$ Es de sobra conocida la aceptación del término "género" a partir de la IV Conferencia Mundial sobre la Mujer celebrada en Beijing en 1995, para identificar las desigualdades injustificadas y la discriminación contra las mujeres por su mera pertenencia al género femenino, lo que supone un estigma de infravaloración jurídico-social. Véase: Declaración de Pekín y la Plataforma para la Acción, recogidos en el Informe de la Resolución adoptada en la Conferencia de 17 de octubre de 1995. Documento A/CONF. 177/20 de 17 de octubre de 1995. En la actualidad, el manejo del término "género" para referirse a la discriminación contra la mujer es comúnmente aceptado entre la doctrina especializada. No obstante, un resumen sobre la polémica que encerró su uso, puede consultarse en: Macías Jara, María (2004).
} 


\section{La idea de Representación política}

Es sabido que resulta complejo referirse a un único significado del término representación. Según el clásico trabajo de PITKIN, se pueden encontrar, al menos, cinco significados de la expresión <representación> (Pitkin, 1985: 5-6). A enumerar: como símbolo, como reflejo de deseos, como cuidado de intereses, como autorización para decidir, como responsabilidad. Según expone Laporta San Miguel, la representación entendida como reflejo de deseos, se suele emplear para incluir lo que se han llamado grupos o sectores sociales como el status, la profesión e, incluso, el género de las personas (Laporta San Miguel, 1989: 130-133). Böckenförde, por ejemplo, también parte de dos vertientes del concepto de representación. Por un lado, habla de "representación en sentido formal" como autorización del pueblo, legitimación y responsabilidad y, por otro lado, "representación de contenido" como reflejo o realización del poder del pueblo (Böckenförde, 1985: 250 y ss). Finalmente, el concepto de representación, comúnmente asumido, al que llega Pitkin hace referencia a la acción de actuar por otros (Pitkin, 1985: 182) ${ }^{2}$. En el caso de la representación política, la actuación se efectúa por cuenta de los representados sin entrar en conflicto con sus deseos o, en caso contrario, dando un buena explicación de por qué los deseos de los representados se hallan en desacuerdo con los intereses que les convienen

Así, la representación política, en palabras de Pitkin (Pitkin, 1985: 233-267):

“[...] es un concierto público e institucionalizado que involucra a muchas personas y grupos y que opera de acuerdo con los complejos modos en que lo hacen los conciertos sociales a gran escala [...]. Es representación si el pueblo está presente en la acción gubernamental, aún cuando no actúe literalmente por sí mismo. En la medida que se trata de una cuestión de actuar sustantivamente por otros, requiere una acción independiente en interés de los gobernados, de una manera al menos potencialmente sensible en la respuesta frente a ellos pero que no esté normalmente en conflicto con sus deseos".

Ahora bien, el hecho de no entrar constantemente en conflicto con sus deseos no implica necesariamente que representación equivalga a contentar a los electores. Por el contrario, no se está ante un gobierno representativo cuando éste muestra el control sobre los ciudadanos, sino cuando estos tienen control sobre las acciones del gobierno de manera que el pueblo actúa a través de su gobierno sin convertirse en mero receptor pasivo de sus actuaciones. No se trata, pues, de que un gobierno represente sólo cuando existe un deseo popular concreto. El gobierno ha de ser sensible, en general, a la existencia de esos deseos, cuando los haya, a largo plazo,

${ }^{2}$ En el mismo sentido, Bobbio (1988: 7). También, Turpin (1987: 79). 
sistemáticamente, y no mediante acciones particulares. Así, el concepto de representación, se configura como una continua tensión entre el ideal y el logro.

Pero la búsqueda de un concepto de representación no es una cuestión de reciente interés. La noción ya se fraguó en la Revolución inglesa de 1688 a partir de la cual comenzó a desarrollarse el "Régimen Parlamentario". En aquel momento, el máximo defensor del Parlamento fue Edmund Burke, quien afirmó que:

"El Parlamento no es un Congreso de embajadores de intereses diferentes y hostiles [...] sino que el Parlamento es una asamblea deliberante de una sola nación, con un solo interés, el del todo, en la cual no son los prejuicios locales los que deben orientarle sino el bien general, resultado de la razón general, del todo. Vosotros elegís un diputado, es verdad, pero cuando lo habéis elegido no es diputado de Bristol, es miembro del Parlamento"”.

También Thomas Hobbes escribió en su obra estrella Leviatán (Hobbes, 1987: 181)

"Dícese que un Estado ha sido instituido cuando una multitud de hombres convienen y pactan, cada uno con cada uno, que a un cierto hombre o asamblea de hombres se le otorgará, por mayoría, el derecho de representar a la persona de todos (es decir, de ser su representante). Cada uno de ellos, tanto los que han votado en pro como los que han votado en contra debe autorizar todas las acciones y juicios de ese hombre o asamblea de hombres, lo mismo que si fueran suyos, al objeto de vivir apaciblemente entre sí y ser protegidos contra otros hombres"

Realmente estas primeras ideas se consolidaron en la antesala de la Revolución francesa. El paso del mandato imperativo propio de concepto de representación jurídica del Derecho privado existente en la Edad Media, al mandato representativo originado en la Revolución francesa, provocó la conexión entre el concepto de representación y el concepto de soberanía en el que se sustituye el principio de soberanía del monarca por el principio de soberanía del parlamento (Vega García, 1985: 25-30).

Así, Carré de Marlberg afirmó que, en la tradición francesa, "el régimen representativo tiene su punto de partida en el sistema de soberanía nacional así como, recíprocamente, el concepto de soberanía nacional conduce esencialmente al régimen representativo" (Carré de Malberg, 1998: 914) $)^{5}$.

\footnotetext{
${ }^{3}$ Discurso electoral pronunciado por Burke en el Colegio de Bristol en 1774. Fragmento reproducido en castellano en Pérez Royo (2003: 641). Y, también, Bobbio (1988: 13). Sobre la teoría de la representación de Edmund Burke, véase Pitkin (1985: cap. 8).

${ }_{5}^{4}$ Para una visión global del nuevo concepto de representación, también, Duso (1998: 32 y ss).

${ }^{5}$ Sobre este particular, Varela Suances destaca la obra de Hermann Heller, La soberanía: contribución a la teoría del derechoestatal y del derecho, de 1965. Varela Suanzes, 1992: 78 y 84).
} 
Pero Sieyès ya había adelantado la esencia de la idea de la Representación indicando en 1789 algunas revolucionarias ideas. En primer lugar, a diferencia de Hobbes, Sieyès consideró que el poder legislativo pertenecía a la nación y no al rey. El abate entendía que la Nación se encuentra allí donde residan todos los habitantes. En consecuencia, a diferencia de Hobbes, para Sieyès, el Estado no merma la libertad de los individuos, sino que la aumenta en tanto es el instrumento necesario para satisfacer sus necesidades ${ }^{6}$.

Así, el pueblo tiene ese canal para identificarse con quien considera que va a dar curso a sus ideas y deseos. De este modo a través del ejercicio del derecho al voto manifiesta su voluntad. Posteriormente, los representantes recogen esa voluntad y la transforman en acción de gobierno pero no sólo para aquellos que les han votado, sino para un todo que el depositario del poder, esto es el pueblo: indivisible y necesariamente conformado por hombres y mujeres.

En este aspecto, De Vega García afirmó que "Los representantes no son soberanos. Sólo la nación. Pero expresan la voluntad de la nación” (Vega García, 1985: 29-30). Turpin (1987: 81) afirmó que "[...] Lo que caracteriza al representante es <querer para la nación>, única soberana".

En segundo lugar, Sieyès pretendió que los diputados fueran auténticos representantes. Y, en tercer lugar, que se distinguiese entre el poder constituyente y el poder constituido, de manera que, según expresó, "por más que la voluntad nacional sea independiente de toda forma, es preciso que adopte una para hacerse entender: veintiséis millones de hombres no se reúnen en una plaza pública" (Maiz, 1991: 64-65). En este sentido, Montesquieu, también apuntó que "La gran ventaja de los representantes es que son capaces de discutir los asuntos. El pueblo en modo alguno lo es [...]" (Montesquieu, 1993: Libro II, cap. II).

Esto hizo que, en contra de Rousseau, Sieyès entendiera dos voluntades nacionales: una constituyente y otra ordinaria, que sería el poder legislativo. En sentido similar, Montesquieu señaló que "la potestad legislativa será confiada al cuerpo que se elegirá para representar al pueblo" (Maiz, 1991: 72 y Carré de Malberg, 1998: 916). También Kant afirmó que el pueblo se expresa sólo a través de representantes hasta el punto de identificar al legislador como el soberano del pueblo o el poder supremo (Duso, 1998: 52).

Sin embargo, antes, Rousseau negó la representación política en tanto que entendió incompatible el régimen representativo con la soberanía popular, que no es susceptible de ser representada. Para el autor ginebrino, la voluntad general del pueblo es inalienable, de modo que el pueblo no puede ser representado más que por sí mismo. La imposibilidad de que pueda representarse la voluntad supone una de las principales premisas del Contrato social, en el que el autor afirmó que "El soberano puede decir lo que quiere tal o cual hombre actualmente, pero no puede decir que lo que este hombre querrá mañana yo lo querré también pues sería absurdo que la voluntad se encadenara para el futuro" (Rousseau, 1990: 33. Libro II, Cap. I). La representación implica, pues, para Rousseau, la anulación del pueblo. "Desde el instante en el que un pueblo se dota de Representantes, no es más libre; no es pueblo”.

\footnotetext{
${ }^{6}$ Un estudio exhaustivo sobre la obra de Sieyès en este extremo, véase en Maiz (1991: 53 y 56).
} 
En contra, Turpin, opinó que, en las condiciones en las que Rousseau planteó la representación, "la Teoría de la representación política no es más que una hábil ficción al servicio de una casta de políticos encargados de hacer prevalecer los intereses de una clase dominante. De ahí, la crítica marxista-leninista al sistema representativo liberal, de ahí también la crisis de la representación al menos en su modalidad parlamentaria por razones tendentes a la ausencia de eficacia pero también de democracia" (Turpin, 1987: 81).

Se quiere hacer una pausa en este punto para conectar este entresijo teórico con la práctica política y poner de manifiesto en este punto que esta situación se refleja en la actualidad. Cogiendo de referencia el panorama político español contemporáneo, considero que existe una cierta tendencia por la que aquellas personas que acceden a un cargo público representativo pretenden una cierta fidelización a la marca que les crea o a los intereses que consideran que les diferencia como marca. Creo que ello encierra problemas de eficacia en la actual configuración de la representación política porque se aleja del ideal y de la responsabilidad adyacente al ejercicio del cargo representativo. Esa responsabilidad no es otra que la de ofrecer salidas viables a las expectativas de la ciudadanía, desde la vocación de servicio público, por la búsqueda del consenso y del bien común.

En ocasiones, el pueblo toma decisiones que dotan a las formaciones políticas de una mayoría suficiente o absoluta para gobernar, probablemente, en busca de seguridad. Sin embargo, el panorama político actual ofrece otra reflexión. El pueblo ya ha realizado su labor escogiendo, en el ejercicio de su derecho de sufragio, la diversidad, la invitación a la representación desde la propia noción de democracia, lo que implica responsabilidad pero, sobre, todo, ofrecer al pueblo que eligió un acuerdo de voluntades que responda a las expectativas. Puede que la elección arriesgue la seguridad que, si se quiere, puede ofrecer un gobierno de mayorías por la necesidad de ampliar la representación diversificándola y dotándola así de mayor democracia, de la necesidad de consensos, pactos y diálogos que consigan ofrecer a la teoría de la representación la democracia que, supuestamente, le es propia.

\section{Soberanía y representación}

Establecido este marco, corresponde a los representantes llegar a eso que el pueblo les conmina, no tanto como si de un mandato imperativo se tratara ni de la voluntad individual en tanto electores, sino en cuanto a representantes de un todo indivisible, único depositario de la soberanía.

En este sentido, Böckenförde, en seguimiento de Leibholz y de Carl Schmitt apuntó que la representación no se refiere a la voluntad 'de todos los individuos', sino a la voluntad empírica del pueblo, pero el pueblo considerado como unidad política distinta del pueblo como existencia natural (Böckenförde, 1985: 9). 
Por último, en reivindicación de la situación del Tercer Estado, Sieyès estableció que los ciudadanos fueran iguales y depositarios de los mismos derechos. Obsérvese que estas son las premisas que luego inspirarían y, finalmente, formarían parte del contenido de la Declaración francesa de Derechos del Hombre y del Ciudadano de 1789 y en el mismo sentido, la Declaración de los Derechos de la Mujer y la ciudadana de 1991 de Olimpia de Gouges (Macías Jara, 2006: 487-491).

Es sabido que en la etapa liberal, los postulados predicados no fueron, en la práctica, tan efectivos como en la teoría. Ahora bien, es innegable que esta época constituye un punto de inflexión de suma importancia a partir del cual no es posible concebir la sociedad si no es a partir de los derechos individualmente considerados. En este punto, la libertad se conjuga con la igualdad para constituir los elementos esenciales y la base de la nueva sociedad.

Una sociedad que, para Sieyès, ha de estar formada por el $<$ Estado Llano $>$, esto es, por un pueblo homogéneo, una nación en la que ya no existan privilegios ni diferencias, sino las sociales. Reivindicar el Tercer Estado implicó afirmar la existencia de un único estado en el que todos son iguales. Partiendo de la base de que, hasta el presente, el Estado Llano no ha sido nada si se le despoja de la clase privilegiada, no vendría a menos, sino a más. Así concluye que el Tercer Estado es todo. Un todo libre y floreciente [...]. Para ello reivindica llegar a ser algo, un mínimo de igualdad [...] para que pueda tener en los Estados generales una influencia al menos igual a la de los privilegiados. Exige un número de representantes, al menos, igual al de las otras dos clases juntas. Se requiere, por lo tanto, un voto por cabeza, no por clase. Sieyès formuló tres peticiones del Estado Llano. La primera: "que los representantes del estado no sean elegidos más que entre los ciudadanos que pertenezcan verdaderamente a él”. En segundo lugar, "que sus diputados sean iguales en número a los de las clases privilegiadas" y, finalmente, "que los Estados generales voten, no por clases, sino por cabezas" (Sieyès, 1988: 38, 43, 44, 51, 52).

Sieyès, por lo tanto, frente a Rousseau, demandó una verdadera representación en la que los representantes actúen por cuenta del representado partiendo de una relación de confianza entre ambos, similar a la confianza que Locke llamara trust (Locke, 1969) ${ }^{7}$. De este modo, el representante se sujeta de algún modo al elector al estar basado en la confianza que es sometida a un control sobre las personas de los representantes y no tanto sobre sus actos (Maiz, 1991: 72 - 73). Esta idea no es lo que, finalmente, se va a redactar en la Constitución francesa de 1791 y que luego se trasladará al resto de Europa: la autonomía absoluta del representante frente al representado, el mandato libre o lo que se conoce como prohibición del mandato imperativo en aras del mandato representativo ${ }^{8}$.

No obstante, de nuevo tomando como referencia el actual escenario político, es posible que se haya hecho un uso hegemónico del mandato representativo. Es decir, la autonomía del

\footnotetext{
${ }^{7}$ Sobre este particular, entre otros, García Roca, 1999: 57 - 58.

${ }^{8}$ Sobre el mandato libre en la Constitución francesa de 1791, Duso, 1998: 10. La diatriba mandato libre versus mandato imperativo, consúltese en Bobbio, 1988: 12 y ss. Entre nosotros, por todos, Presno Linera, 2000: 65 y ss. Recuérdese que en la vigente Constitución española de 1978, la prohibición de mandato imperativo se encuentra expresamente recogida en el artículo 67.2.
} 
representante frente al representado es necesaria para preservar el propio principio representativo tal y como se ha fraguado. Ahora bien, si observamos esa confianza como un vehículo para el ejercicio de la responsabilidad de los representantes para con los representados, creo que la autonomía no ha de convertirse en hegemonía, en poder ilimitado, en arbitrariedad e irresponsabilidad, en definitiva.

En verdad, es esa confianza, - sin que ésta sea confundida con una suerte de mandato imperativo -, la que legitima la actuación de los representantes porque esa confianza es depositada en virtud de la tensión de la que se viene hablando entre el ideal querido por el pueblo y el logro que pueda conseguirse. Y será en esa tarea en la que los representantes hayan de esforzarse, no en el sentido de recibir ningún tipo de instrucción o mandato sobre sus actos, sino sometiéndose a los principios de la representación que, valga la redundancia, representan y, sobre todo, desde la responsabilidad inherente a la representación. El margen de discrecionalidad para con los actos y la autonomía de las decisiones de los representantes, no exime la responsabilidad de llegar a los acuerdos o pactos que, al menos, en abstracto, conozcan o tengan en consideración el ideal de lo ya expresado desde la voluntad popular.

En este plano, la voluntad popular ha dejado latente tras las últimas elecciones celebradas el pasado diciembre de 2015, la necesidad de una reformulación del Estado, optando por una mayor democracia representativa participativa que intenta dejar atrás obsoletos modelos de fidelización de la marca de partido y apuesta por la elaboración de pactos y de acuerdos sobre aquello que afecte a los derechos e intereses de la ciudadanía. Sin embargo, aún queda por ver la respuesta popular que tendrá lugar como consecuencia de la incapacidad de la clase política actual para cumplir con el ideal presentado. Quizá, ante la irresponsabilidad política de asumir la función de representar, volvamos asistir a un repliegue del pueblo, al status quo que ofrece la seguridad de las mayorías pero ojalá que no...

Así pues, el modelo de representación que, como es sabido, se perpetuara en la tradición francesa $y$, en general, europea reunió las siguientes características. En primer lugar, la Asamblea de diputados expresa la voluntad de la nación. En segundo lugar, el diputado representa a la entera nación y no a los electores concretos que lo han elegido. Y, en tercer y último lugar, el diputado goza de independencia frente a los electores representados.

Posteriormente, Jhon Stuart Mill profundizó sobre la idea de Representación al abordarla bajo la premisa de que la mejor forma de gobierno era el representativo en su obra de 1861 llamada, precisamente, Del Gobierno representativo. Esta obra estaba basada en los postulados de libertad que enunciara en la anterior Sobre la libertad, de 1859. Así, tras desarticular los argumentos pro-gobierno absolutista o despótico, Stuart Mill explicó que:

“[...] el ideal de la mejor forma de gobierno es la que inviste de la soberanía a la masa reunida de la comunidad teniendo cada ciudadano no sólo voz en el ejercicio del poder sino, de tiempo, en tiempo, intervención real por el desempeño de alguna función local o general”. Así, “[...] es evidente que el único gobierno que satisface por completo todas las 
exigencias del estado social es aquel en el cual tiene participación el pueblo entero. Pero puesto que en toda comunidad que exceda los límites de una pequeña población, nadie puede participar personalmente sino de una porción muy pequeña de los asuntos públicos, el tipo ideal de un gobierno perfecto es el gobierno representativo" (Stuart Mill, 1994: 34$35)$.

En esta línea, en nuestros días, Laporta San Miguel ha señalado que la representación política no es más que un modelo para dar respuesta a una situación en la que "un conjunto de individuos interrelacionados por reglas se encuentran en la tesitura de tener que actuar como conjunto y no en términos de sus individualidades [...] de manera que representan al grupo humano como un conjunto de individuos que han realizado una operación interna de división del trabajo para hacer posible su actuación como grupo" (Laporta San Miguel, 1989: 126-128) ${ }^{9}$.

También, Presno Linera, ha afirmado que "la participación política de los ciudadanos - y, añado, ciudadanas - directa o a través de representantes es el fundamento de la democracia. En la actualidad, la complejidad de las sociedades ha hecho que sea comúnmente aceptado y aconsejable la participación a través de representantes sin que ello implique una anulación de la voluntad de los destinatarios de las decisiones tomadas por los representantes" (Presno Linera, 2000: 41) $)^{10}$.

Dada la incapacidad, en ocasiones, de los representantes de conseguir formar gobiernos, no parece que se comprenda la idea de actuar como conjunto, es decir, que para representar es necesario abandonar la individualidad, no así la ideología política, claro, en virtud del valor de pluralismo político y de libertad pero si es preciso asumir que cuando el candidato deviene representante lo es junto a otros formando un conjunto avocado necesariamente al diálogo porque, como tal, tiene que conseguir representar a otro conjunto, esto es, el pueblo soberano, que se presenta como un todo a pesar de haber manifestado su voluntad individual en el ejercicio de un derecho.

Por lo tanto, Stuart Mill apoyó la participación de todos los afectados en la elaboración de la decisión y, en consecuencia, cada uno es consciente de sus propios intereses y el más competente para decidir sobre ellos. Lo importante no es tanto el interés en sí, sino la decisión sobre quién ha de cuidar tales intereses (Laporta San Miguel, 1989: 121-122 y Bobbio, 1988: 3 y ss). Lo significativo es que quien decida a quién va a otorgar el poder de decidir sea el pueblo soberano.

\footnotetext{
${ }^{9}$ El autor explica cómo Heller estableció en similares términos a los de Kelsen, que "no es posible que se mantenga en actividad la unidad colectiva de acción sin el obrar de un órgano que cuide de un modo consciente, tanto de determinar los fines como de su realización".

${ }^{10} \mathrm{El}$ autor puntualiza que "el hecho de que la participación sea directa o a través de representantes sólo implica la forma de organizar el sistema de legitimación democrática lo que hará que la elección de una u otra fórmula se realice precisamente en función del mayor grado de garantía del objetivo del principio democrático".
} 
Así, representar implica decidir y decidir implica poder, en este caso, político. De este modo, no será posible referirse a la noción de representación política, en el pensamiento político actual, sin aludir a la idea de poder, de su ejercicio y, también, de su legitimación (Duso, 1998: 18). Legitimar el poder supone, correlativamente, limitarlo a través de la separación entre el soberano y quien actúa en su nombre mediante el mecanismo de la democracia representativa (Pablo Lucas Murillo de la Cueva, 1997: 138).

Sin embargo, parece que la legitimación como base para dotar al poder de legitimidad para ejercerlo puede estar en quiebra. Creo que el problema está precisamente en esa legitimidad porque ostentar por los representantes el mecanismo teoríco-jurídico y, por lo tanto, legítimo que ofrece la democracia representativa no parece concederles correlativamente la legitimidad, de naturaleza política, que necesitan para que aquellos que depositaron la confianza en los representantes como conjunto, continúen haciéndolo. En este plano, el pueblo observa una transgresión de la decisión que ya tomó en tanto electorado, con la que comunicó a los representantes la necesidad de diálogo, de apertura, de pacto y de consenso. Si los representantes, lejos de abordar el mensaje y verse como una unidad conjunta de acción, desoyen la decisión mostrada por los ciudadanos y ciudadanas, queda rota la confianza en ellos depositada, dándose un vacío o una distancia difícilmente salvable entre la legitimación jurídica y la legitimidad política.

En este aspecto, puede explicarse cierta crisis de la representación y la necesidad de contemplar otros medios que lleven a una regeneración democrática o bien que los representantes comprendan su función y aborden desde ella las decisiones políticas que consigan reducir la distancia entre el ideal y el logro. En cualquier caso, según la actual noción de representación política en conexión con el principio de soberanía, es el pueblo, como un todo indivisible, quien elige a sus representantes que son los que legislan y deciden por ellos, en su nombre, habiendo escuchado la decisión sobre quien o quienes han de cuidar de sus intereses. Es por eso que una vez elegidos, esos representantes no actúan como reflejo único de los intereses de la parte que les eligió, sino en nombre de todos y de todas. Esa es la idea de democracia.

\section{La democracia sin calificativos. ¿Quién es el pueblo soberano?}

En la elaboración inicial de la idea de la representación, con el fin de hacer partícipe al pueblo soberano para tomar decisiones que afectaban al conjunto de la nación, se reivindicó, como es sabido, la igualdad de castas o clases pero no así la igualdad de género. Posteriormente, la lucha por la reivindicación del derecho al sufragio universal hizo que el reconocimiento del derecho al voto y a ser elegido representante en las Constituciones modernas de principios del siglo XX consolidase, al menos, sobre el papel, la igualdad en la 
participación política, eliminando formalmente la exclusión por razón de clases y de género (Ventura Franch, 1999: 79). La consecución de la igualdad de género encierra un componente inequívoco que la hace prioritaria. Se trata de su esencia con el ser humano, de modo que mientras que las clases o castas se van modificando a lo largo de los tiempos y responden a una naturaleza cambiante, el género tiene una naturaleza permanente de manera que la dualidad de la Humanidad y de la Nación siempre es el resultado de su propia configuración.

No obstante, el reconocimiento de derechos, ya en el siglo XXI no ha determinado su materialidad y es sabido que, a falta de una Ley nacional de Igualdad, la igualdad real continúa siendo una quimera. En el caso de la igualdad de género, la Ley Orgánica para la igualdad efectiva de mujeres y hombres de 2007, realizó un importante intento, mediante el principio de presencia equilibrada, para la consecución de la igualdad en el contexto de la representación política, entre otros (Macías Jara, 2011: 223-249).

Aún en el 2016, con dificultades para estrenar Legislatura, tras las elecciones celebradas el pasado 20 de diciembre, la exclusión de pacto de las mujeres sigue patente. Personalmente, me dio cierto pudor el júbilo que supuso el nombramiento de las actuales vicepresidentas de la Mesa del Congreso, no por ocupar su merecido lugar, por supuesto, sino porque me dio la sensación de que se disfrazó de logro lo que continúa siendo concesión. Creo que el conjunto de los representantes no han aceptado aún al género femenino como parte del cuerpo representativo con capacidad real de poder, un poder ostentado por las mujeres y aquí me refiero al término mujeres en plural conscientemente, con la idea de que ello signifique muchas.

La soberanía y la representación en democracia ha de ser ejercida por hombres y mujeres en plural -, no por una o por dos o por LA mujer o por la que llega, en ocasiones primera y única (Macias Jara, Agenda Pública, 16 de junio de 2015), o la que siempre estuvo, sino por LAS mujeres, como cuerpo soberano, como parte natural del proceso, como síntoma de LA democracia. Y no una democracia incompleta o una deficiente o una paritaria o una representativa paritaria o una mejor, sino como la única democracia conceptualmente posible, sin calificativos ni apelativos. Parece que en esta próxima Legislatura, aún por constituir, la proporción de mujeres representantes, llegaría por primera vez al $40 \%$ o una cifra muy cercana en el Congreso ${ }^{11}$. Se sigue vendiendo como logro una situación que viene impuesta por Ley desde el año 2007 y teniendo en cuenta que estamos en el año 2016, lo único que simboliza esa cifra, a mi juicio, es que sortear el cumplimiento de una ley para que lo desigual consiga ser legal solo puede hacerse desde la discriminación porque, por lo demás, sobran las razones. Stuart Mill y Taylor Mill se refirieron a ello al afirmar que:

"Cuando un perjuicio tiene alguna influencia sobre los sentimientos, se ve en la desagradable necesidad de tener que dar razones, se cree que ha hecho suficiente cuando ha afirmado de nuevo el mismo punto que está en discusión, en frases que recurren al sentimiento preexistente. Así, muchas personas piensan que han justificado

\footnotetext{
${ }^{11}$ http://www.elmundo.es/espana/2015/12/21/5677b95ae2704eb5408b45e9.html [26/05/2016]
} 
suficientemente las limitaciones del campo de acción de la mujer cuando han dicho que las ocupaciones de que se excluye a las mujeres son poco femeninas, y la esfera propia de la mujer no es la política, o la notoriedad, sino la vida privada y doméstica" (Stuart Mill y Taylor Mill, 1973: 126).

En este sentido, es realmente importante hablar de una construcción teórica de la representación y, por lo tanto, de un pacto social global que aúne intereses de los individuos que conforman el pueblo soberano, hombres y mujeres, como un todo en el que, diferentes o no, puedan manifestar su forma de tomar decisiones y de ejercer la política. Hay masculino universal o femenino universal, según se vea, porque igual da expresar todos - los individuos que todas -las personas-, por lo que no hay una única Humanidad ni una única Nación: la masculina, sino una dual (Martínez Sempere, 2000: 136-141).

De este modo, en la representación de la Nación, el pueblo se muestra como un todo indivisible en el que todos y todas representan a todos y a todas. Sin embargo, hasta los últimos tiempos, y en contra de lo que dispusieran el artículo tres de la Declaración de Derechos del Hombre y del Ciudadano de 1789 y también la Declaración de Derechos de la Mujer y de la Ciudadana de Olimpia de Gouges de 1791, la representación del pueblo se ha materializado en una sola clase selectiva de personas, excluyendo a la otra mitad y dividiendo así la soberanía en dos.

Desde esta perspectiva, Barrère Unzueta, señaló que las mujeres sufren una discriminación añadida a la de cualquier otro colectivo, por su pertenencia al género femenino (Barrère Unzueta, 1997: 28-29). En este sentido, se habla de las mujeres como categoría o grupo, entre otros. Pero las mujeres no escogen serlo. No se está ante un supuesto de opciones, como elegir la religión que se profesa. Tampoco las mujeres son una minoría numérica, como puede serlo una raza o una etnia respecto a la dominante, ni son un grupo particular, ni una categoría o colectivo social. Es importante comprender esto porque el empoderamiento político de las mujeres no supone una concesión en base a su posición social, sino un derecho propio individual.

Al tiempo, el reconocimiento de la dualidad del pueblo soberano no está en colisión con la indivisibilidad de su esencia en cuanto a cuerpo representado ni en cuanto a conjunto de representantes, por lo que la existencia y el reconocimiento de una Nación dual no ha de conducir a la estéril idea de pretender dividir la soberanía y la representación política en dos o en tantas categorías como tipología ciudadana exista. El género femenino no reivindica un conjunto de intereses que se vean reflejados en un órgano como el Parlamento, sino que la reivindicación es, en sí misma, la igualdad para representar y hacer efectivo el derecho de sufragio pasivo en el Parlamento. Porque no se ha alcanzado una igualdad real, cualitativa es por lo que la exclusión del ejercicio del poder y de los pactos políticos de las mujeres continúa dándose, produciéndose a lo sumo una igualdad de superficie o ficticia que no hace más que 
maquillar la realidad y convertirse en espejismo de sí misma. La soberanía sin pueblo soberano es lo que, en definitiva, debilita el propio pacto democrático.

\section{A modo de conclusión}

Históricamente, como es sabido, la democracia representativa se ha defendido contra un sistema considerado más utópico basado en la democracia directa, sólo posible en sociedades de mínima población. Así, la democracia representativa se viene justificando como el sistema más factible para llevar a cabo los intereses del pueblo soberano.

En la configuración actual de la representación política es sabido que ésta, según expone Lucas Murillo de la Cueva, legitima al poder. Y, precisamente, sólo desde la representación democrática se hace posible la limitación de ese poder, al existir separación entre el soberano y quien actúa en su nombre, así como la salvaguarda de los derechos fundamentales frente al exceso de poder de los representantes (Lucas Murillo de la Cueva, 1997: 138-140). No es así en la democracia de identidad entre gobernantes y gobernados donde no es posible limitar el poder. Por ello, la democracia realizada es la democracia representativa, que es la verdadera democracia, siendo así la representación democrática al imponerse el sufragio universal y la reafirmación de la soberanía popular. En este aspecto, la exigencia de elegir a los representantes constituye la esencia de la representación. Lo democrático es el mecanismo de elección de los representantes, de ahí su importancia.

Bobbio estableció que una democracia es representativa en el sentido de tener un órgano en el que las decisiones colectivas vengan tomadas por el representante, respetando, a través de este representante, los diversos grupos de opinión o de interés que se han formado en la sociedad (Bobbio, 1988: 256). Este respeto que reposa en la voluntad de los representados, expresada mediante el ejercicio del derecho al voto puede verse como una carencia de la representación actual, en tanto los representantes parecen más ocupados y preocupados de defender marcas o distintivos de marcas que de representar al soberano que les eligió, un pueblo soberano formado por hombres y mujeres ${ }^{12}$. La fragmentación o categorización del Parlamento no tiene que ver con la pluralidad política ni con la inclusión de los géneros, sino con la incapacidad para asumir la voz del pueblo que, en uso de los recursos que ofrecen la legitimación a los representantes, exige más democracia, no como medio, sino como premisa y fin. Ello precisa de diálogo, de libertad participativa y de igualdad. Ahora, corresponde a aquellos dotarse de la legitimidad política para responder como grupo de acción al cuerpo soberano. De lo contrario, iremos camino a una democracia cada vez más debilitada, que se presenta casi como una quimera, con un pueblo soberano ausente ante la imposibilidad de

\footnotetext{
${ }^{12}$ Cabe señalar que, según exponía Olimpia de Gouges en el artículo tercero de su Declaración de los Derechos de la Mujer y de la Ciudadana, "El principio de toda soberanía reside esencialmente en la Nación, que no es más que la reunión de la Mujer y del Hombre (...)".
} 
realizar conexión alguna entre el ideal por él expresado y el logro que lleve a cabo el representante.

La democracia es libertad de participación pero la libertad no puede ir sino de la mano de la igualdad en la representación. Así, pues, la democracia sólo es posible si la igualdad de mujeres y hombres se presenta como una premisa política derivada de los principios que constituyen un cuerpo político, tal como sucede con el sufragio universal y con la separación de poderes (Saavedra Ruiz (Dir.), 1999: 277).

Así, el modelo de democracia representativa debe responder a la exigencia de incluir a hombres y mujeres en conexión con la actual concepción de la representación, la indivisibilidad de la soberanía y la naturaleza dual de la Humanidad y de la Nación por derecho propio e individual.

La soberanía necesariamente incluye el ejercicio del poder por un todo indivisible, que legitima al representante por mandato representativo - no imperativo -, por lo que pretender la categorización o la parcelación parlamentaria no resulta compatible con la idea de representación ni de soberanía. Al tiempo, la democracia precisa del ejercicio de la representación por lo que la exclusión de la soberanía y de la representación popular del género femenino, como cuerpo electoral y sujeto soberano es, asimismo, irreconciliable con la igualdad y libertad de participación en Democracia. La conexión entre el ideal y el logro es lo que hace de la democracia representativa una herramienta útil, pero solo si ese ideal puede ser expresado por todas y todos y solo si el pacto constitutivo de una reconstrucción socio-política del Estado es realizado por los y las representantes como depositarios de esa misión, se podrá terminar con esta suerte de democracia debilitada ante la que nos encontramos.

No resulta jurídicamente empírico ni, hasta que no pueda suceder, si quiera demostrable que si hubieran sido cuatro las mujeres que se hubieran sentado al frente de las negociaciones políticas en esta fallida investidura, hubieran sido exitosas. Puede que tampoco sea jurídicamente relevante qué valores y habilidades incorpore quién. Pero se quiere invitar a la reflexión sobre la necesidad de dejar de hacer concesiones por el poder político tradicional, de algún modo, con patrones políticos masculinos, hacia la sociedad, hacia las mujeres, hacia el pueblo soberano, de derechos que les son propios a ellas o de voluntades que pertenecen al pueblo y que se ignoran obligándoles a emitirlas de nuevo en unas repetitivas e innecesarias elecciones generales, por la sola razón de que los representantes, supuestos líderes, han sido incapaces de hacer lo único para lo que se les eligió; esto es, responsabilizarse de su cargo público y hacer política.

Por lo tanto, es la capacidad de los hombres y mujeres, representantes comprometidos, que comparten el poder político, de generar un nuevo modelo de representación que apueste por la apertura, la escucha, el diálogo, el consenso, la voluntad de mejorar y la vocación de servicio público, lo que hará posible fortalecer la democracia. En ocasiones, parece necesario recordar qué se entiende por democracia $\mathrm{y}$, sin embargo, creo que solo puede hablarse de aquella democracia avanzada que, sin adjetivos, implica comprender que en su esencia y noción queda 
implícito todo lo que encierra la igualdad y la libertad efectiva de los hombres y las mujeres para producir y garantizar los mecanismos para la expresión de la voluntad popular. Eso es la Democracia.

\section{BIBLIOGRAFÍA}

- Barrère Unzueta, M. Ángeles (1997): Discriminación, Derecho antidiscriminatorio y acción positiva a favor de las mujeres. San Sebastión: Instituto Vasco de Administración Pública, Cuadernos Cívitas.

- Bobbio, Norberto (1988): "Rappresentanza e interesi”. En: Gianfranco Pasquino (ed.): Rappresentanza e democrazia. Bari: Laterza

- Böckenförde, Ernst. W. (1985): “Democrazia e rappresentanza”. En: Quaderni Costituzionali, $\mathrm{n}^{\circ} .2$, agosto, pp. 237-239.

- Carré de Malberg, Raymond (1998): Teoría general del Estado. México: Fondo de Cultura Económica.

- Vega García, Pedro (1985): "Significado constitucional de la representación política". En: Revista de Estudios Políticos (Nueva Época), nº. 44, marzo-abril, pp. 25-46.

- Duso, Giuseppe (1998): Il contrato sociale nella filosofia política moderna. Milán: Franco Angeli.

- García Roca, Javier (1999): Cargos públicos representativos. Un estudio del artículo 23.2 de la Constitución. Madrid: Editorial Aranzadi.

- Heller, Hermann, (1965): La soberanía: contribución a la teoría del derecho estatal y del derecho. México: UNAM.

- Hobbes, Thomas (1987): Leviatá. México: Fondo de Cultura Económica.

- Laporta San Miguel, Francisco Javier (1989): "Sobre la Teoría de la democracia y el concepto de representación política: algunas propuestas para debate". En Doxa, nº. 6, pp. 121142.

- Locke, John (1969): Ensayo sobre el gobierno civil. Madrid: Aguilar.

- Lucas Murillo De Le Cueva, Pablo (1997): "Los problemas constitucionales de la representación política". En: Revista Jurídica del Perú, Año XLVII, nº 11, abril-junio, pp. 137150.

- Macías Jara, María, (2006): “Declaración de los Derechos de la Mujer y de la Ciudadana de Olimpia de Gouges y Declaración de Seneca Falls. La voz de las mujeres”. En: Luis García San Miguel (Ed.), Filosofía Política. Las grandes obras, Dykinson, Madrid, pp. 487-491.

- Macías Jara, María, (2011): “El principio de presencia equilibrada en la Ley Orgánica para la Igualdad efectiva de mujeres y hombres". En: Anuario Facultad de Derecho, IV. Universidad de Alcalá, pp. 223- 249.

- Macías Jara, María (2015): “La primera mujer, ¿o la única?”. En: Agenda Pública, 16 de junio de 2015 [en línea] Disponible en: http://agendapublica.es/la-primera-mujer-o-la-unicaante-la-igualdad-ficticia-de-genero/ [26/02/2016]. 
- Maiz, Ramón (1991): "Estado constitucional y gobierno representativo. En: E. J. Sieyès", Revista de Estudios Políticos, nº. 72, Abril-Junio, pp. 45-88.

- Macías Jara, María (2004): "Polémica en torno al concepto de género", Actas del Congreso XXV años de Estudio de género. En: Pau Serrano Magdaleno (coord. pub.) y Carme Pinyana Garí (coord. edic.): Mujeres Sabias: entre la teoría y la práctica. Castellón de la Plana: Fundación ISONOMÍA para la Igualdad de Oportunidades, Publicacions de la Universitat Jaume I, Castelló de la Plana, pp. 362-368.

- Martínez Sampere, Eva (2000): "La legitimidad de la democracia paritaria”. En: Revista de Estudios Políticos, nº. 107, pp. 136- 141.

- Montesquieu, Charles Louis de Secondat Barón de (1993): Del espíritu de las leyes. Barcelona: Altaya. (Libro II, Cap. II).

- Pérez Royo, Javier (2003): Curso de Derecho Constitucional. Madrid: Marcial Pons.

- Pitkin, Hanna F. (1985): El concepto de representación. Madrid: Centro de Estudios Constitucionales.

- Presno Linera, Miguel Ángel (2000): "Los Partidos Políticos en el Sistema Constitucional Español”: En: Cuadernos Aranzadi del Tribunal Constitucional, nº. 5, pp. 1-49

- Rousseau, Jean Jaques, (1990): Del contrato social. Madrid: Alianza Editorial, (7 reimpresión).

Sieyès, Emmanuel J (1988): ¿Qué es el Estado llano?. Madrid: Centro de Estudios Constitucionales.

- Stuart Mill, John (1994): Del Gobierno representativo. Madrid: Tecnos. $2^{\mathrm{a}}$ ed.

- Stuart Mill, John Y Taylor Mill, Harriet (1973): Ensayos sobre la igualdad sexual. Barcelona: Península.

- Turpin, Dominique (1987) : "Représentation et démocratie". En : Droits. Revue Française de Théorie juridique, $\mathrm{n}^{\mathrm{o}}$. 6, Presses Universitaires de France, Paris, pp. 78-83.

- Varela Suanzes, Joaquín (1992): "Algunas reflexiones sobre la soberanía popular en la Constitución española". En: Revista Española de Derecho Constitucional, nº. 36, septiembrediciembre, pp. 71-104.

- Ventura Franch, Asunción (1999): Las Mujeres y la Constitución Española de 1978. Madrid: Instituto de la Mujer, Ministerio de Trabajo y Asuntos Sociales. Serie Estudios, $\mathrm{n}^{\mathrm{o}} .60$. 